\title{
Association of Thrombolysis in Myocardial Infarction (TIMI) Risk Score with Angiographic Severity of Coronary Artery Disease In Patients with Non-ST Elevation Acute Coronary Syndrome
}

A.B.K. BASHIRUDDIN ${ }^{1}$, MOHAMMAD IBRAHIM CHOWDHURY ${ }^{1}$, BIPLOB BHATTACHAR.JEE ${ }^{1}$, ABUL HOSSEN SHAHIN ${ }^{1}$, SYED ALI AHSAN ${ }^{2}$, MRM MANDAL ${ }^{2}$ SUKANTA DHAR ${ }^{1}$, IQBAL MAHMUD ${ }^{1}$, MD. SAHADAT HOSSAIN ${ }^{1}$

${ }^{1}$ Department of Cardiology, Chattogram Medical College, Chattogram, ${ }^{2}$ Department of Cardiology, Bangabandhu Sheikh Mujib Medical University (BSMMU), Dhaka.

Address of Correspondence: Dr. A.B.K. Bashiruddin, Department of Cardiology, Chattogram Medical College, Chattogram. E-mail: abk.bashiruddin@gmail.com

\begin{abstract}
:
Background: Clinical guidelines recommend that optimal management of acute coronary syndrome (ACS) should include patient risk stratification. Predicting the anatomical extension of coronary artery disease (CAD) is also potentially useful for clinical decision.

Objective: The objective of our study was to determine whether the TIMI risk score correlates with the angiographic extent and severity of CAD in patients with NSTE- ACS.

Materials and Methods: This was a cross-sectional observational study carried out in the Department of Cardiology, Chattogram Medical College Hospital (CMCH) from September 2017 to May 2018. A total of 200 patients diagnosed with NSTE-Acute Coronary Syndrome were included as sample by purposive sampling method. TIMI risk score for each patient was calculated and the patients were stratified into 3 groups according to the TIMI risk score: low risk (0-2); intermediate risk (3-4); high risk (5-7). The severity of the CAD was assessed by Vessel score and Gensini score.

Result: The mean $\pm S D$ of the age of study population was $53.7 \pm 10.8$ years (range 37-77) and 142 (71\%) were male. Regarding cardiovascular risk factors, 137 (68.5\%) patients had diabetes mellitus, 83 (41.5\%) had dyslipidaemia, 155 (77.5\%) had hypertension, 136 (68\%) were current smoker and 70 (35\%) had a family history of CAD. The Gensini score was higher in patients at high risk TIMI group $(p<0.001)$. Moreover, there was a signiûcant positive correlation between the TIMI and Gensini score $(r=0.446, p<0.001)$. TIMI score can predict significant CAD moderately well (area under the curve 0.661, $p=0.001$ ). Patients with TIMI score $>4$ were more likely to have significant three vessel CAD (65.9\%) versus those with TIMI risk score 3-4 (17.9\%) and TIMI risk score $<3(2 \%)(p<0.001)$.

Conclusion: Study showed the TIMI score is significantly correlated with the extent of CAD as assessed by the Gensini score. It is accurate for predicting severe CAD among NSTE-ACS patients.
\end{abstract}

Key words: Acute coronary syndrome; Correlation; Coronary artery disease; TIMI score; coronary angiography, Gensini score.

University Heart Journal 2019; 15(2): 68-73

Introduction:

Cardiovascular diseases account for more than 17 million death globally each year. It contributes $30 \%$ of all deaths. $80 \%$ of those occur in low-income and middle-income coun-tries. This figure is expected to grow to 23.6 million by the year 2030 . Coronary artery disease (CAD) alone caused 7 million deaths worldwide in 2010. It is an increase of $35 \%$ since $1990 .{ }^{1}$ Estimates from the Global Burden of Disease Study suggests that by the year 2020 the South
Asian part of the world (India, Pakistan, Bangladesh, Nepal) will have more individuals with atherothrombotic cardiovascular disease than any other region. ${ }^{2}$ The exact prevalence of CAD in Bangladesh is not known. Only a limited number of small-scale epidemiological studies are available. Probably the prevalence of CAD was first reported in 1976 , which was $0.33 \%{ }^{3}$ More recent data indicates the CAD prevalence is $1.85 \%$ to $3.4 \%$ in rural population and it is $19.6 \%$ in an urban population. ${ }^{4}$ The 
clinical presentations of CAD include silent ischemia, stable angina pectoris, acute coronary syndrome, heart failure and sudden death. ${ }^{5}$ The incidence of NSTE-ACS, both absolute and relative to ST elevation myocardial infarction, is increasing, probably as a result of demographic changes in the population, including progressively increasing numbers of older persons and higher rates of diabetes mellitus. ${ }^{6}$ Current NSTE-ACS guidelines recognize the importance of early risk stratification in the management of NSTE-ACS and recommend an integrated approach to risk assessment. ${ }^{7}$ Several model of risk scores are developed in predicting short and mid-term outcomes in patients with acute coronary syndrome and to distinguish the patients at the highest risk or an adverse outcome, who may benefit from aggressive therapies. The PURSUIT (2000), TIMI (Thrombolysis In Myocardial Infarction) (2000), GRACE (2003) and FRISC (2004) risk score models are well validated with this respect. Recently (2008) the HEART risk score was developed. ${ }^{8}$

The TIMI score was derived from clinical trial databases. Although TIMI risk score is an important and validated tool for assessing prognosis but studies evaluating its association with the extent of CAD is limited. In addition to prognostic assessment, predicting the anatomical extension of CAD is potentially useful for clinical decision. The objective of our study was to determine whether the TIMI risk score correlates with the angiographic extent and severity of CAD in patients with NSTE-ACS undergoing coronary angiography Cardiology Department of Chattogram Medical College Hospital, Chattogram, Bangladesh.

\section{Materials and Method:}

\section{Study design and patients}

This cross-sectional observational study was conducted on 200 Non-ST elevation ACS patients admitted in Cardiology department of Chattogram Medical College and Hospital (CMCH), Chattogram, Bangladesh for CAG during September 2017 to May 2018. Patients were included if CAG was done within one month of NSTE-ACS. Patients were excluded on the background of refusal to give consent, severe co-morbid conditions like severe uncontrolled DM, ESRD etc.

\section{Study procedure:}

All patients admitted in the Department of Cardiology, $\mathrm{CMCH}$ with NSTE-ACS fulfilling the inclusion criteria were considered for inclusion in the study. Informed written consent was taken from each patient before enrollment.
Meticulous history was taken and detailed clinical examination was performed and recorded in predesigned structured proforma. History was taken about chest pain, history of diabetes, hypertension, dyslipidaemia, smoking, family history of $\mathrm{CAD}$, aspirin intake, prior coronary artery disease. Demographic data such as age, sex, occupation was recorded. Risk factors profile including smoking, hypertension, diabetes, dyslipidaemia and family history of CAD was noted.

Laboratory investigations Serum Troponin I, Random Blood Sugar, Fasting Lipid Profile were done. ECG: 12 lead resting ECG was done at a paper speed of $25 \mathrm{~mm} / \mathrm{s}$ and $10 \mathrm{~mm}$ standardization at admission. Serum Troponin I concentration was determined by immunometric assay within 12 hours of hospitalization. The level of troponin I $>1 \mathrm{ng} / \mathrm{ml}$ was considered as positive cardiac marker. Coronary Angiography was performed by percutaneous femoral or radial approach. Coronary angiograms were obtained for each coronary vessel in e"2 projections. Analysis of the coronary angiograms were performed visually by experienced interventional cardiologists working in $\mathrm{CMCH}$ catheterization laboratory. The severity of the CAD was assessed by Gensini score. Gensini score $>36$ was considered as severe CAD.

\section{Data analysis:}

After collection data were entered into Microsoft Excel to generate a master sheet. Next, they were fed into SPSS Statistical Software (23.0 version) for data processing and analysis. Descriptive statistics were computed and presented as either means and standard deviations or median and interquartile ranges for continuous variables. Frequencies and percentages were computed for gender, risk factors (hypertension, diabetes, smoking, dyslipidaemia and family history of CAD). Chi-square test was applied to determine the proportions difference among three TIMI risk groups. Considering that both TIMI score and the Gensini score showed non-normal distribution (Kolmogorov-Smirnov test), the statistical analyses were mainly non-parametric. Aiming at assessing the association between TIMI risk scores and CAD extension, some analyses were used. First, the linear association of risk score with the Gensini score was assessed by use of Spearman correlation. Second, the Independent sample Kruskal-Wallis test was used to compare the Gensini score values among the three TIMI risk groups. Third, the receiver-operating characteristics (ROC) curve was used to test the predictive accuracy of TIMI risk score regarding the presence of obstructive CAD. Significant prediction occurred when the area under the ROC curve was 
statistically different from 0.5 . P value of less than 0.05 was considered as significant.

\section{Results:}

The objective of our study was to determine whether the TIMI risk score correlates with the angiographic extent and severity of CAD in patients with NSTE-ACS.A total of 200 patients diagnosed with NSTE-ACS were enrolled as sample by purposive sampling method. TIMI risk score for each patient were calculated and the patients were divided into groups according to the TIMI risk score: low risk (0-2); intermediate risk (3-4); high risk (5-7).

Most of the study population was $<65$ years of age (78\%). The mean age of the patients was $53.7 \pm 10.8$ years (range: 37-77years) (Table 1). Majority (71\%) of the patients were male with male to female ratio about 2.45:1 (Figure 1). Out of 200 NSTE-ACS patients 137 (68.5\%) patients were diabetic, $155(77.5 \%)$ were hypertensive, $136(68 \%)$ were smokers, 70 (35\%) had positive family history ischemic heart disease and 83 (41.5\%) were dyslipidaemic (Figure 2).

Among the TIMI risk score variables: chest pain was most prevalent and involved $131(66 \%)$ patients, followed by 107 (54\%) patients used aspirin within seven days, ST segment depression $>0.5 \mathrm{~mm}$ was observed in 98 (49\%) patients, troponin I was raised in $63(32 \%)$ and $15(8 \%)$ patients had prior CAD (Figure 3 ).

According to CAG, out of 200 patients, 70 (35\%) had two vessel CAD, 48 (24\%) had normal coronary artery, 41 (20.5\%) with single vessel CAD and $41(20.5 \%)$ had three vessel CAD. Median Gensini score was 24 (IQR: 12-40.7). Among Gensini score 137(68.5\%) had score $<36$ (Non severe) and 63 (31.5\%) had score $>36$ (severe CAD).

Mean age as well as patient with age e 65 years was higher in intermediate and high risk groups in comparison to low risk group. Female outnumbered the males in low risk group (Table III). Statistically significant association was found $(\mathrm{p}<0.001)$.

CAD risk factors were significantly more prevalent in intermediate and high risk groups in comparison to low risk group. Statistically significant result was found ( $p$ $<0.001$ ) (Table IV). TIMI risk score variables were significantly more prevalent in intermediate and high risk groups in comparison to low risk group (Table V).

Mean Gensini score were 20 $\pm 12.9,31.9 \pm 15.2$ and 51.9 \pm 34.1 , in low TIMI risk group, intermediate group and high risk group respectively and the difference of median Gensini score was statistically significant $(\mathrm{p}<0.001)$.
Table VII shows that, angiographic severity was increased as the TIMI risk group increased, with most of the patients in non severe CAD had low TIMI risk group in contrast to most of the patients in the severe CAD group had high TIMI risk group.

The discriminator accuracy of TIMI risk score to predict significant CAD was analyzed by ROC curve. The TIMI score discriminated accurately patients with or without obstructive CAD - area under the ROC curve of 0.661 ; 95\% CI: 0.573-0.748; $<<0.001$ (Figure 6).

In our study correlation co-efficient between TIMI risk score and Gensini score was $\mathrm{r}=0.446(\mathrm{p}<0.001)$. We found that Gensini score was positively and significantly associated with the TIMI score (Figure 7).

As shown in Table VIII, as the TIMI score increases the extent of CAD is also increased. Among the 100 patients with low risk TIMI score, majority 69 (69\%) had normal angiography finding and rest 31 (31\%) had single vessel disease. Patients with intermediate TIMI risk group majority $(89.7 \%)$ had two vessel disease and patents with high risk TIMI score majority $(81.8 \%$ ) had three vessel disease.

\section{Table-I}

Distribution of the study population by their age $(N=200)$

\begin{tabular}{lcc}
\hline Age, in years & Frequency $(\mathrm{n})$ & Percentage $(\%)$ \\
\hline Category & & \\
$<65$ & 156 & 78 \\
$\geq 65$ & 44 & 22 \\
Mean \pm SD & & $53.7 \pm 10.8$ \\
Range & & $37-77$ \\
\hline
\end{tabular}

$\mathrm{SD}=$ Standard deviation

Table-II

Gensini score of the study population $(N=200)$

\begin{tabular}{lc}
\hline Parameters & Number (\%) \\
\hline Number of vessel involved & \\
No vessel involved & $48(24 \%)$ \\
Single vessel & $41(20.5 \%)$ \\
Double vessel & $70(35 \%)$ \\
Triple vessel & $41(20.5 \%)$ \\
Gensini score & \\
d 36 (Non severe) & $137(68.5 \%)$ \\
$>36($ Severe) & $63(31.5 \%)$ \\
Mean \pm SD & $30.7 \pm 23.5$ \\
Median (IQR) & $24(12-40.7)$ \\
Range & $0-120$ \\
\hline
\end{tabular}

$\mathrm{N}=$ Number of study population

$\mathrm{n}=$ Number in each group

$\mathrm{SD}=$ Standard deviation; IQR: Interquartile range 
Table-III

Age and sex distribution in different TIMI risk group of the study population $(n=200)$

\begin{tabular}{llcccc}
\hline Variables & & \multicolumn{3}{c}{ TIMI risk group } & P value \\
\cline { 3 - 5 } & & $\begin{array}{c}\text { Low risk } \\
(\mathrm{n}=100)\end{array}$ & $\begin{array}{c}\text { Intermediate risk } \\
(\mathrm{n}=56)\end{array}$ & $\begin{array}{c}\text { High risk } \\
(\mathrm{n}=44)\end{array}$ & \\
\hline \multirow{2}{*}{ Age } & & $99(99 \%)$ & $49(87.5 \%)$ & $8(18.2 \%)$ & $<0.001^{*}$ \\
Sex & $\geq 65$ years & $1(1 \%)$ & $7(12.5 \%)$ & $36(81.8 \%)$ & $<0.001^{*}$ \\
& Female & $42(42 \%)$ & $10(17.9 \%)$ & $6(13.6 \%)$ & \\
\hline
\end{tabular}

Data are presented as frequency (percentage) if not mentioned otherwise.

*P value derived from Chi-square test and significant.

\section{Table-IV}

Distribution of the patients by their risk factors profile and TIMI risk group

\begin{tabular}{lcccc}
\hline Variables & \multicolumn{3}{c}{ TIMI risk group } & P value \\
\cline { 2 - 4 } & $\begin{array}{c}\text { Low risk } \\
(\mathrm{n}=100)\end{array}$ & $\begin{array}{c}\text { Intermediate risk } \\
(\mathrm{n}=56)\end{array}$ & $\begin{array}{c}\text { High risk } \\
(\mathrm{n}=44)\end{array}$ & $0.001^{*}$ \\
\hline Smoking & $56(56 \%)$ & $46(82.1 \%)$ & $34(77.3 \%)$ & $0.002 *$ \\
Hypertension & $68(68 \%)$ & $46(82.1 \%)$ & $41(93.2 \%)$ & $<0.001 *$ \\
DM & $56(56 \%)$ & $40(71.4 \%)$ & $41(93.2 \%)$ & $<0.001 *$ \\
Dyslipidaemia & $23(23 \%)$ & $29(51.8 \%)$ & $31(70.5 \%)$ & $<0.001 *$ \\
H/O IHD & $18(18 \%)$ & $26(46.4 \%)$ & $26(59.1 \%)$ & \\
\hline
\end{tabular}

Data are presented as frequency (percentage).

H/O: History of; IHD: Ischemic heart disease; DM: Diabetes mellitus

*P value derived from Chi-square test and significant.

Table-V

Distribution of patients by TIMI risk score variables and TIMI risk group

\begin{tabular}{lcccc}
\hline Variables & \multicolumn{3}{c}{ TIMI risk group } & P value \\
\cline { 2 - 4 } & $\begin{array}{c}\text { Low risk } \\
(\mathrm{n}=100)\end{array}$ & $\begin{array}{c}\text { Intermediate risk } \\
(\mathrm{n}=56)\end{array}$ & $\begin{array}{c}\text { High risk } \\
(\mathrm{n}=44)\end{array}$ & \\
\hline Chest pain & $41(41 \%)$ & $48(86 \%)$ & $42(96 \%)$ & $<0.001^{*}$ \\
H/O prior CAD & $1(1 \%)$ & $3(5 \%)$ & $11(25 \%)$ & $<0.001^{*}$ \\
Aspirin use & $18(18 \%)$ & $46(82 \%)$ & $43(97 \%)$ & $<0.001^{*}$ \\
ST deviation & $14(14 \%)$ & $42(75 \%)$ & $42(96 \%)$ & $<0.001^{*}$ \\
Raised Troponin I & $8(8 \%)$ & $17(30 \%)$ & $38(86 \%)$ & $<0.001^{*}$ \\
\hline
\end{tabular}

Data are presented as frequency (percentage).

H/O: History of; CAD: Coronary artery disease

*P value derived from Chi-square test and significant.

Table-VI

Association between TIMI score and Gensini score $(n=200)$

\begin{tabular}{lccc}
\hline TIMI risk score & \multicolumn{2}{c}{ Gensini score } & P value \\
\cline { 2 - 4 } & Mean $\pm \mathrm{SD}$ & Median $(\mathrm{IQR})$ & \\
\hline Low risk group $(0-2), \mathrm{n}=100$ & $20 \pm 12.9$ & $18.5(12-27.8)$ & $<0.001^{*}$ \\
Intermediate risk group $(3-4), \mathrm{n}=56$ & $31.9 \pm 15.2$ & $32(22.5-44)$ & \\
High risk group $(5-7), \mathrm{n}=44$ & $51.9 \pm 34.1$ & $52(23-23.5)$ & \\
\hline
\end{tabular}

SD: Standard deviation; IQR: Interquartile range

*P value derived from Kruskal-Wallis test and significant. 
Table-VII

Association between TIMI risk group and CAD type

\begin{tabular}{lccc}
\hline TIMI risk group & \multicolumn{2}{c}{ CAG findings } & P value \\
\cline { 2 - 3 } & $\begin{array}{c}\text { Non sever } \\
(\text { Gensini score } \leq 36)\end{array}$ & $\begin{array}{c}\text { Severe } \\
(\text { Gensini score }>36)\end{array}$ & \\
\hline Low risk group (0-2), $\mathrm{n}=100$ & $83(60.6 \%)$ & $17(27.0 \%)$ & $<0.001 *$ \\
Intermediate risk group (3-4), $\mathrm{n}=56$ & $34(24.8 \%)$ & $22(34.9 \%)$ & \\
High risk group (5-7), $\mathrm{n}=42$ & $20(14.6 \%)$ & $24(38.1 \%)$ & \\
Total & $137(68.5 \%)$ & $63(31.5 \%)$ & \\
\hline
\end{tabular}

Data are presented as frequency (percentage).

CAG: Coronary angiography; CAD: Coronary artery disease

*P value derived from Chi-square test and significant.

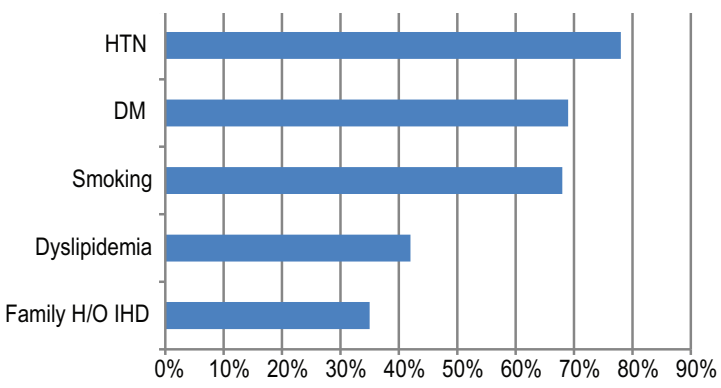

Fig.-1: Distribution of the cardiac risk factors among the patients $(n=200)$. DM: Diabetes mellitus; HTN: Hypertension; H/O: History of; IHD: Ischemic heart disease

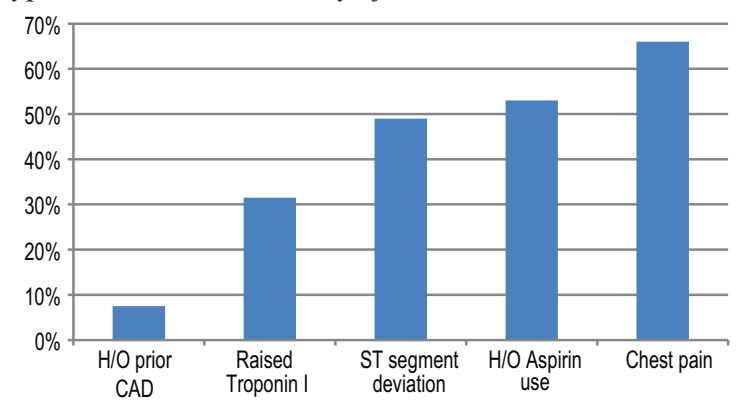

Fig.-2: TIMI risk score variables in the study population.

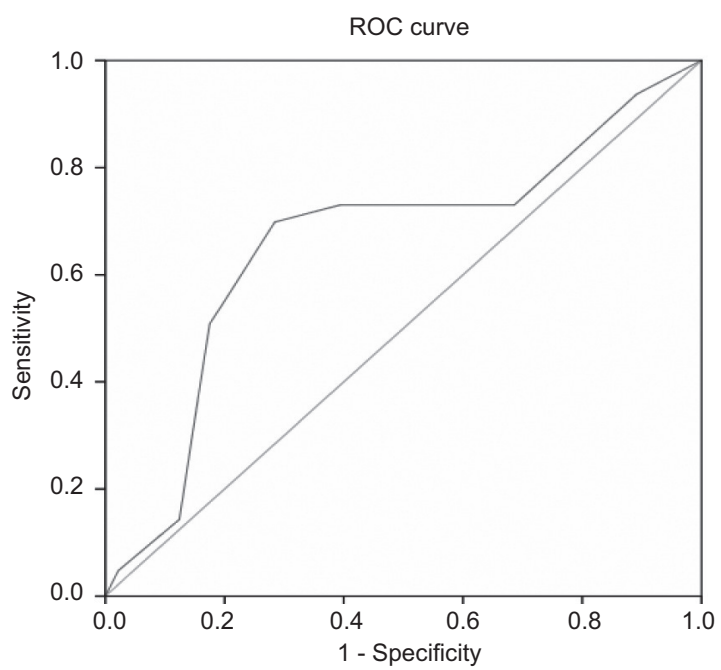

Fig.-3: ROC curve of the TIMI score for detecting significant $C A D$

\section{Conclusion:}

The present study shows a significant correlation between TIMI clinical risk score and the angiographic Gensini score as well as with the number of diseased vessel. We demonstrated that the TIMI risk score is significantly correlated with the extent of CAD as assessed by the Gensini score. It is accurate for predicting severe CAD among NSTE-ACS patients.

\section{References:}

1. Wong ND. Epidemiological studies of CHD and the evolution of preventive cardiology, Nat Rev Cardiol. 2014; 11(5):27689.

2. Chakraborty B, Zaman F, Sharma AK. Combating Coronary Artery Disease in South Asia-What is special? Bangladesh Journal of Cardiology 2009; 1(2): 88-90.

3. Malik A. Congenital and acquired heart diseases (a survey of 7062 persons). Bangladesh Med Res Counc Bull, 1976; 2(2): $115-9$.

4. Islam A K, Majumder A A. Coronary artery disease in Bangladesh: a review. Indian heart journal, 2013; 65(4): 42435 .

5. Roffi M, Patrono C, Collet JP, Mueller C, Valgimigli M, Andreotti, $\mathrm{F}$ et al. ESC Guidelines for the management of acute coronary syndromes in patients presenting without persistent ST-segment elevation: Task Force for the Management of Acute Coronary Syndromes in Patients Presenting without Persistent ST-Segment. Eur Heart J. 2016; 37(3): 267-315.

6. Giugliano RP, Cannon CP, Braunwald E. Non-ST Elevation acute coronary syndrome. In: Mann DL, Zipes DP, Libby P, Bonow RO, eds. Braunwald's Heart Disease: A Textbook of Cardiovascular Medicine, Tenth Edition ed. Philadelphia: Saunders, an imprint of Elsevier; 2015; 1155-1157.

7. Khalill R, Han L, Jing C, Quan, H. The use of risk scores for stratification of non-ST elevation acute coronary syndrome patients. Experimental \& Clinical Cardiology, 2009; 14, e25e30.

8. Bueno H, Ferna'ndez-Avile's F. Use of risk scores in acute coronary syndromes. Heart, 2012; 98(8): 162-68. 
9. Joshi SR. Metabolic syndrome-emerging clusters of the Indian phenotype. J Assoc Physicians India, 2003; vol.51,pp.445-6.

10. Roy SS, Azam STMA, Khalequzzaman M, Ullah M, Rahman MA. GRACE and TIMI risk scores in predicting the angiographic severity of non-ST elevation acute coronary syndrome. Indian Heart Journal, 2017; 1396: 4 pages. https:/ /doi.org/10.1016/j.ihj.2018.01.026.

11. Saha T, Khalequzzaman M, Akanda MAK, Saha S, Tushar AZ, Ahmed R, Saha GK, Ullah M. Association of GRACE Risk Score with Angiographic Severity of Coronary Artery Disease in patients with ST Elevation Myocardial Infarction. Cardiovas. J, 2015; 8(1):30-34.

12. MahmoudyNayel AE, Sabet S. CRT-104 Grace Score and the Angiographic Severity of Coronary Artery Disease in Patients with Non-ST-Elevation Acute Coronary Syndrome. JACC: Cardiovascular Interventions, 2014; 7, S7-S8.

13. Mega JL., Morrow DA, Sabatine MS, Zhao XQ, Snapinn SM, Dibattiste PM, et al. Correlation between the TIMI risk score and high-risk angiographic findings in non-ST-elevation acute coronary syndromes: observations from the Platelet Receptor Inhibition in Ischemic Syndrome Management in Patients Limited by Unstable Signs and Symptoms (PRISM-PLUS) trial. American heart journal 2005; 149 5, 846-50.

14. Zheng XY, Meng XK, Li WG, Yang J, Wei G, Fang R. Clinical study on value of severity of patient with coronary artery disease evaluated with the thrombosis in myocardial infarction risk score. Zhongguo Wei Zhong Bing Ji Jiu Yi Xue 2004; 16: 239-41.

15. Garcia S, Canoniero M, Peter A, de Marchena E, Ferreira A. Correlation of TIMI risk score with angiographic severity and extent of coronary artery disease in patients with nonST-elevation acute coronary syndromes. Am J Cardiol 2004; 93:813-952.
16. Lakhani MS, Qadir F, Hanif B, Farooq S, Khan M. Correlation of Thrombolysis in Myocardial Infarction (TIMI) risk score with extent of coronary artery disease in patients with acute coronary syndrome. J Pak Med Assoc. 2010; 60(3):197-200.

17. Barbosa CE, Viana M, Brito M, Sabino M, Garcia G, Maraux M, et al. Accuracy of the GRACE and TIMI Scores in Predicting the Angiographic Severity of Acute Coronary Syndrome. Arquivos Brasileiros de Cardiologia. 2012; 99(3): 818-824.

18. Yan AT, Yan RT, Tan M, Casanova A, Labinaz M, Sridhar K, et al. Risk scores for risk stratification in acute coronary syndromes: useful but simpler is not necessarily better. Eur Heart J.2007; ;28(9):1072-8.

19. Mega JL, Morrow DA, Sabatine, MS, Zhao XQ, Snapinn SM, DiBattiste PM, et al. Correlation between the TIMI risk score and high-risk findings in non-ST-elevation acute coronary syndromes: observations from the Platelet Receptor Inhibition in Ischemic Syndrome Management in Patients Limited by Unstable Signs and Symptoms (PRISM-PLUS) trial. Am heart j.2005; 149(5):846-50.

20. Correia LCL, Freitas R, Bittencourt AP, Souza AC, Almeida $\mathrm{MC}$, Leal J, et al. Prognostic value of GRACE scores versus TIMI score in acute coronary syndromes. Arq Bras Cardiol. 2010; ;94(5):576-582.

21. Antman EM, Cohen M, Bernink, PJ, McCabe CH, Horacek T, Papuchis G, et al. The TIMI risk score for unstable angina/ Non-ST elevation MI: A method for prognostication and therapeutic decision making. JAMA, 2000; 284(7):835-842.

22. Chase M, Robey, JL, Zogby KE. Prospective validation of the Thrombolysis in Myocardial Infarction Risk Score in the emergency department chest pain population. Ann Emerg Med, 2006; 48:252-259.

23. Pollack CV, Sites FD, Shofer FS. Application of the TIMI Risk Score for unstable angina and non-ST elevation acute coronary syndromes to an unselected emergency department chest pain population. Acad Emerg Med, 2006; 13:13-18. 